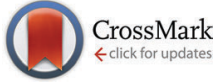

Cite this: Phys. Chem. Chem. Phys., 2016, 18, 31072

Received 23rd August 2016, Accepted 19th October 2016 DOI: $10.1039 / c 6 c p 05835 c$

www.rsc.org/pccp

\title{
Initial steps for the thermal decomposition of alkaline-earth metal amidoboranes: a cluster approximation $\dagger$
}

\author{
A. V. Pomogaeva* and A. Y. Timoshkin
}

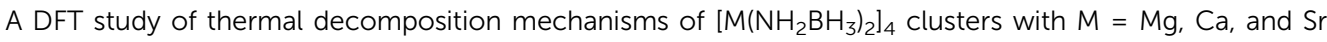
is presented. Multi-step reaction pathways leading to elimination of the first $\mathrm{H}_{2}$ molecule are explored at the M06/TZVP level of theory. For all studied $M$, the clusters adopt similar structures and exhibit similar transformations along the reaction pathways. Their activation energies decrease in the order $\mathrm{Mg}<\mathrm{Ca}$ $\leq$ Sr. Four metal atoms in the cluster form a rigid planar construction that is found to be nearly unchanged during all transformations. Cleavage of the $\mathrm{B}-\mathrm{H}$ bond in the environment of alkaline-earth metal atoms leads to the "capture" of the released $\mathrm{H}$ atom by neighboring metal atoms with the formation of a $\mathrm{M}_{3} \mathrm{H}$ moiety. While the activation energies for the cleavage of $\mathrm{H}^{\delta-}$ can be as low as 14.3, 22.6 and $23.3 \mathrm{kcal} \mathrm{mol}^{-1}$ for $\mathrm{M}=\mathrm{Mg}$, Ca and $\mathrm{Sr}$, respectively, barriers for the subsequent cleavage of $\mathrm{H}^{\delta+}$ via destruction of the $\mathrm{M}_{3} \mathrm{H}$ moiety are about twice larger.
\end{abstract}

\section{Introduction}

Development of materials with properties appropriate for transportable hydrogen storage is an advanced field in modern chemistry. ${ }^{1,2}$ The excellent gravimetric and volumetric hydrogen density of ammonia borane and its derivatives attracts persistent interest in this class of compounds. ${ }^{3,4}$ It was found that alkali-metal amidoboranes $\mathrm{LiNH}_{2} \mathrm{BH}_{3}$ and $\mathrm{NaNH}_{2} \mathrm{BH}_{3}$ release more hydrogen at lower temperatures than pure ammonia borane and also suppress borazine release. ${ }^{5}$ However, release of a significant amount of ammonia was observed under thermal decomposition of alkalimetal amidoboranes. ${ }^{6-10}$

Alkaline-earth amidoboranes $\mathrm{Mg}\left(\mathrm{NH}_{2} \mathrm{BH}_{3}\right)_{2} \quad(\mathrm{MgAB}){ }^{11}$ $\mathrm{Ca}\left(\mathrm{NH}_{2} \mathrm{BH}_{3}\right)_{2}(\mathrm{CaAB}),{ }^{12}$ and $\mathrm{Sr}\left(\mathrm{NH}_{2} \mathrm{BH}_{3}\right)_{2}(\mathrm{SrAB})^{13}$ are known laboratory species which also demonstrate improved dehydrogenation properties compared to ammonia borane. First, $\mathrm{CaAB}$ was obtained as a THF adduct, ${ }^{14}$ then pure $\mathrm{CaAB}$ was synthesized by ball milling of $\mathrm{CaH}_{2}$ and $\mathrm{BH}_{3} \mathrm{NH}_{3} \cdot{ }^{12}$ These forms have different dehydrogenation properties. THF containing CaAB releases $\mathrm{H}_{2}$ mainly in the temperature range from 120 to $245{ }^{\circ} \mathrm{C},{ }^{14}$ while the solvent free $\mathrm{CaAB}$ eliminates hydrogen at $\sim 80^{\circ} \mathrm{C}$ with peaks at 100 and $140{ }^{\circ} \mathrm{C} .{ }^{12} \mathrm{H}_{2}$ release from $\mathrm{SrAB}$ starts at about $60{ }^{\circ} \mathrm{C}$ and the decomposition becomes violent as the temperature

Inorganic Chemistry Group, Institute of Chemistry, St. Petersburg State University, Universitetskaya nab. 7/9, St. Petersburg, 199034, Russia.

E-mail: avpomogaeva@cc.spbu.ru

$\dagger$ Electronic supplementary information (ESI) available: Fig. S1-S6, Table S1, and optimized structures of all clusters. See DOI: 10.1039/c6cp05835c increases to $93{ }^{\circ} \mathrm{C}$. MgAB exhibits three overlapping dehydrogenation steps with the peak temperatures at 104, 162 and $223{ }^{\circ} \mathrm{C}^{11}$ Activation energies for the three dehydrogenation steps are 20.1, 27.7 and $28.4 \mathrm{kcal} \mathrm{mol}^{-1}$. The third dehydrogenation step of MgAB is found to be mildly endothermic and the thermolysis of MgAB yields no volatile by-products. ${ }^{11}$ Dehydrogenation of $\mathrm{CaAB}$ also is not accompanied by the release of borazine. ${ }^{12}$ The release of $\mathrm{B}_{2} \mathrm{H}_{6}$ and $\mathrm{NH}_{3}$ was noticed during the thermal decomposition of SrAB. ${ }^{13}$

Experimental success in the synthesis of alkaline-earth amidoboranes has stimulated related theoretical studies. A number of works based on solid state theory are devoted to the prediction of crystal structure, ${ }^{15}$ dehydrogenation mechanisms, ${ }^{16}$ possible intermediate products of the dehydrogenation reaction, ${ }^{17}$ hydrogen diffusion pathways, ${ }^{18}$ and optical ${ }^{19}$ and elastic ${ }^{20}$ properties of metal amidoboranes (MAB). Advantages of $\mathrm{MAB}$ over pure ammonia borane (lower dehydrogenation barriers, a less exothermic overall dehydrogenation reaction and borazine suppression) are attributed to the ionic character of bonds in MAB and the catalytic role of the metal. However, the detailed dehydrogenation mechanism is still unclear. Kim et al. ${ }^{21}$ presented a comprehensive $a b$ initio study of the mechanisms and kinetics of $\mathrm{H}_{2}$ release in monomers and dimers of MAB. They concluded that oligomerization (O-path) and non-oligomerization (D-path) pathways are competitive. The oligomerization pathway is found to be more favorable for alkali-metal amidoboranes. In contrast, the release of $\mathrm{H}_{2}$ via direct transfer of $\mathrm{H}^{-}$, abstracted by the metal cation from the $\mathrm{BH}_{3}$ group, to $\mathrm{H}^{+}$of the $\mathrm{NH}_{2}$ group of the same $\mathrm{NH}_{2} \mathrm{BH}_{3}$ unit is more favorable in the case of CaAB and MgAB. 
The activation energy of the release of the first $\mathrm{H}_{2}$ molecule from $\mathrm{CaAB}$ and $\mathrm{MgAB}$ is equal to $36 \mathrm{kcal} \mathrm{mol}^{-1}$ at the MP2/6$311++\mathrm{G}^{* *}$ level of theory. Yuan et al. ${ }^{22}$ reported that the release of the first $\mathrm{H}_{2}$ molecule from the $\mathrm{CaAB}$ dimer is kinetically more favorable if it does not involve the $\mathrm{Ca}$ atom in the dehydrogenation transition state. No pathways of formation of an oligomeric $\left[\mathrm{BH}_{3} \mathrm{NH}_{2} \mathrm{BH}_{2} \mathrm{NH}_{2}\right]^{-}$unit were found at the DFT(PBE/PAW) level of theory. ${ }^{22}$

These theoretical studies reveal the importance of intermolecular interactions for the particular development of chemical reactions in MAB. The crystal structure of these compounds features a network based on weak $\mathrm{M}-\mathrm{N}$ and $\mathrm{M}-\mathrm{H}\left(\mathrm{BH}_{3}\right)$ interactions. Cluster approximation is an intermediate approach between molecular and solid state computations. It allows tracking of molecular transformations in the chemical reaction pathways taking into account the local atomic environment. ${ }^{23,24}$ Herein, we present a comparative study of possible pathways leading to the release of the first molecule of $\mathrm{H}_{2}$ from tetrameric clusters $\left[\mathrm{M}\left(\mathrm{NH}_{2} \mathrm{BH}_{3}\right)_{2}\right]_{4}$, where $\mathrm{M}=\mathrm{Mg}(\mathbf{1}), \mathrm{Ca}(2)$, and $\mathrm{Sr}(3)$.

\section{Results and discussion}

\section{A. Structure of $\left[\mathrm{M}\left(\mathrm{NH}_{2} \mathrm{BH}_{3}\right)_{2}\right]_{4}$ tetramers}

In the present work, a tetrameric cluster, $\left[\mathrm{Ca}\left(\mathrm{NH}_{2} \mathrm{BH}_{3}\right)_{2}\right]_{4}(2)$, was obtained by optimization of a cutout from crystalline CaAB. $\mathrm{CaAB}$ adopts a monoclinic structure with the $C_{2}$ space group. ${ }^{12}$ Each Ca atom is coordinated with two $\mathrm{NH}_{2}$ and four $\mathrm{BH}_{3}$ groups (Fig. 1a). The minimal distance between $\mathrm{H}^{+}$and $\mathrm{H}^{-}$of adjacent layers is about $2.4 \AA$, i.e. no dihydrogen bonds occur. This observation points out that dehydrogenation proceeds within a layer. A chosen piece of crystalline structure is shown in Fig. 1a and the optimized geometry of the resultant $C_{2 \mathrm{~h}}$ symmetric tetrameric cluster is presented in Fig. 1b (projection onto the $X Y$ plane).

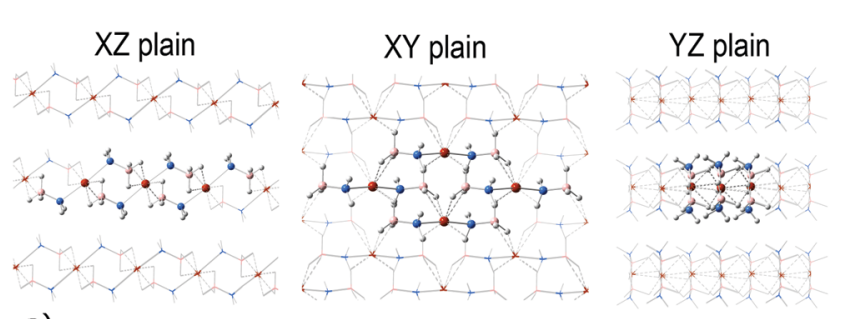

a)

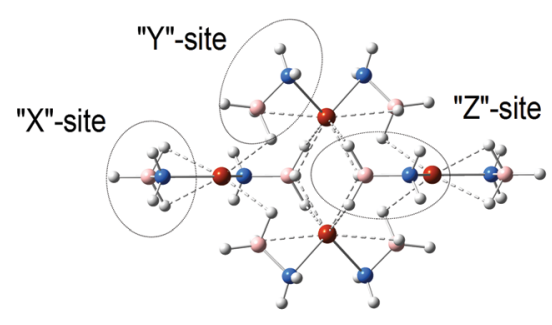

b)

Fig. 1 Three projections of the experimental crystalline structure of $\mathrm{CaAB}^{12}$ (a) and the optimized structure of $\left[\mathrm{Ca}\left(\mathrm{NH}_{2} \mathrm{BH}_{3}\right)_{2}\right]_{4}$ (b). Molecules extracted from the crystal structure are shown in ball $\&$ bond format, other molecules are shown as a wireframe. Red refers to $\mathrm{Ca}$ atoms, blue to $\mathrm{N}$, orange to $\mathrm{B}$ and white to $\mathrm{H}$ atoms. The $\mathrm{Ca}-\mathrm{H}\left(\mathrm{BH}_{3}\right)$ bond network is shown by dashed lines. " $x$ "-, " $y$ "- and " $z$ " positions of $\mathrm{NH}_{2} \mathrm{BH}_{3}$ units are marked with ovals.
The $z$-axis is chosen to be perpendicular to the layer. $\mathrm{NH}_{2} \mathrm{BH}_{3}$ groups in the cluster can be classified according to their positions as shown in Fig. 1b. Expectedly, the Ca-N-B angles are the most affected by optimization, which is reflected in the formation of additional $\mathrm{Ca}-\mathrm{H}\left(\mathrm{BH}_{3}\right)$ bonds with $x$ - and $y-\mathrm{NH}_{2} \mathrm{BH}_{3}$ groups. The environment of $\mathrm{BH}_{3}$ groups in $z-\mathrm{NH}_{2} \mathrm{BH}_{3}$ is less affected upon the optimization of the cutout from the crystal tetramer. Overall, $\mathrm{Ca}-\mathrm{H}\left(\mathrm{BH}_{3}\right)$ distances in the resultant tetramer are in the range $2.30-2.45 \AA$. In general, optimization leads to bond shortening with respect to the experimental structure. While all experimental B-N bond lengths in the crystal are $1.575 \AA$, the optimized values in the tetramer are $1.570,1.543$, and $1.527 \AA$ in $x$-, $y$-, and $z-\mathrm{NH}_{2} \mathrm{BH}_{3}$, respectively. The respective values of $\mathrm{Ca}-\mathrm{N}$ distances are 2.352, 2.400, and $2.461 \AA$, while in the CaAB crystal the $\mathrm{Ca}-\mathrm{N}$ bond lengths are $2.383 \AA$.

Several initial experimental attempts of the synthesis of pure MgAB failed, ${ }^{14,25}$ which led to the conclusion that the condensed charge on $\mathrm{Mg}^{2+}$ cations leads to structural instability. However, pure MgAB was finally obtained, ${ }^{11}$ but unfortunately, the crystal structure of the compound has not been determined. A computational modelling ${ }^{15}$ predicts that $\mathrm{MgAB}$ adopts a structure in the same space group as experimentally known CaAB. In the present study, we assumed the structure of $\left[\mathrm{Mg}\left(\mathrm{NH}_{2} \mathrm{BH}_{3}\right)_{2}\right]_{4}$ (1) to be similar to that of 2 . The optimized structure of $\mathbf{1}$ (Fig. S1 in the ESI $\dagger$ ) indeed resembles that of 2 though the pattern of the $\mathrm{M}-\mathrm{H}\left(\mathrm{BH}_{3}\right)$ contacts is slightly different. $\mathrm{Mg}-\mathrm{H}\left(\mathrm{BH}_{3}\right)$ distances are in the range 2.02-2.25 $\AA$. $\mathrm{Mg}-\mathrm{N}$ bond lengths are 2.026, 2.052 and $2.136 \AA$, and $\mathrm{B}-\mathrm{N}$ bond lengths are 1.589, 1.592 and $1.522 \AA$ in $x$-, $y$-, and $z-\mathrm{NH}_{2} \mathrm{BH}_{3}$, respectively.

$\mathrm{SrAB}$ adopts a similar structural type in the crystal as $\mathrm{CaAB}$ with different atomic coordinates. Positions of hydrogen atoms in the unit cell of SrAB were not determined. ${ }^{13}$ To be consistent, we assumed the geometry of the tetrameric cluster $\left[\mathrm{Sr}\left(\mathrm{NH}_{2} \mathrm{BH}_{3}\right)_{2}\right]_{4}(3)$ to be similar to that of $\mathbf{2}$. In the optimized structure of $\mathbf{3}$, $\mathrm{Sr}-\mathrm{H}\left(\mathrm{BH}_{3}\right)$ distances are in the range 2.47-2.60 $\AA$. Sr-N bond lengths are $2.518,2.586$, and $2.632 \AA$, and $\mathrm{B}-\mathrm{N}$ bond lengths are $1.571,1.539$, and $1.526 \AA$ in $x$-, $y$-, and $z-\mathrm{NH}_{2} \mathrm{BH}_{3}$, respectively.

In the following discussion the energy values are reported with respect to the optimized tetrameric clusters 1,2 , and 3.

\section{B. Cleavage of $\mathrm{B}-\mathrm{H}$ bonds and $\mathrm{M}_{3} \mathrm{H}$ moiety formation}

$\mathrm{B}-\mathrm{H}$ dissociation energies in $\mathrm{MAB}$ are lower than $\mathrm{N}-\mathrm{H}$ dissociation energies, ${ }^{18}$ thus, the first obvious step in the dehydrogenation mechanism is the cleavage of the $\mathrm{B}-\mathrm{H}$ bonds. Metal atoms in the considered tetramers form a diamond-shaped arrangement in the $X Y$ plane (Fig. 1b). Atomic charges of $\mathrm{Mg}$ from the natural population analysis are 1.398 for atoms arranged parallel to the $X$-axis and $1.500 \bar{e}$ for atoms arranged parallel to the $Y$-axis. The respective charges of $\mathrm{Sr}$ are 1.157 and $1.260 \bar{e}$. The NBO analysis provides the respective charges for $\mathrm{Ca}$ in $2,0.857$ and $0.930 \bar{e}$, to be somewhat smaller than those for $\mathrm{Sr}$ in 3 because of the higher natural population of valence orbitals. B-H bonds of $z-\mathrm{NH}_{2} \mathrm{BH}_{3}$ directed toward the $X Y$ plane are the longest (for example, $1.259 \AA$ compared to $1.229 \AA$ for other $\mathrm{B}-\mathrm{H}$ bonds in this $\mathrm{BH}_{3}$ group in 2) with the largest negative charge at $\mathrm{H}$ atoms (NBO charges are $-0.100 \bar{e} ;-0.070 \bar{e}$; and $-0.114 \bar{e}$ for 1,2 , and 3 , respectively). 


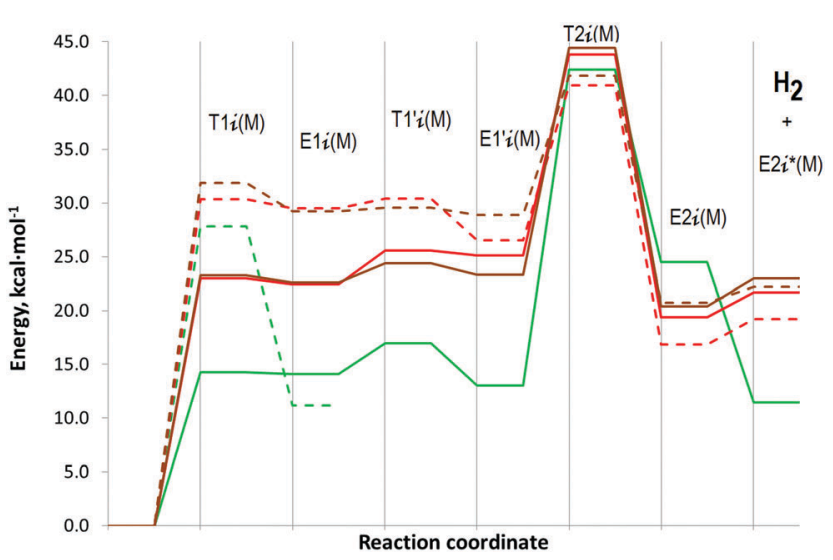

Fig. 2 Energy diagram for dehydrogenation pathways in $\left[\mathrm{M}\left(\mathrm{NH}_{2} \mathrm{BH}_{3}\right)_{2}\right]_{4}$, $\mathrm{M}=\mathrm{Mg}$ (green), $\mathrm{Ca}(\mathrm{red})$ and $\mathrm{Sr}$ (brown). Lines $(i=z)$ refer to the $z$-path and dashed lines $(i=y)$ refer to the $y$-path.

Cleavage of these $\mathrm{B}-\mathrm{H}$ bonds leads to the hydrogen atom takeover by three neighboring metal cations in $\mathbf{E 1 z}(\mathbf{M})$ local minima (see the energy diagram in Fig. 2). It was shown earlier that the formation of a $\mathrm{Li}_{3} \mathrm{H}$ moiety is a key feature of dehydrogenation pathways in LiAB. ${ }^{2324}$ The analogous pyramidal $\mathrm{M}_{3} \mathrm{H}$ moiety is also formed upon activation of alkaline-earth amidoboranes. The highest bonding orbital of $\mathbf{E 1 z}(\mathbf{C a})$ is delocalized over the $\mathrm{Ca}_{3} \mathrm{H}$ moiety (Fig. 3). Geometrical parameters of the $\mathrm{M}_{3} \mathrm{H}$ moieties in $\mathbf{E 1 z}(\mathbf{M})$ are provided in the ESI $\dagger$ (Table S1). The removed hydrogen atom gains significant charge in the environment of the three metal cations. It has a natural charge of $-0.580,-0.358$ and $-0.484 \bar{e}$ for $\mathrm{M}=\mathrm{Mg}, \mathrm{Ca}$, and $\mathrm{Sr}$, respectively. The transition state leading to the cleavage of the $\mathrm{B}-\mathrm{H}$ bond $\mathbf{T 1 z}(\mathbf{M})$ is only slightly higher than $\mathbf{E 1 z}(\mathbf{M})$. The energy barriers that should be crossed to split the B-H bond are 23.0 and $23.3 \mathrm{kcal} \mathrm{mol}^{-1}$ for 2 and 3, respectively. It is much lower for 1 , only $14.3 \mathrm{kcal} \mathrm{mol}^{-1}$.

Alternatively, the $\mathrm{H}$ atom could be removed from $y-\mathrm{NH}_{2} \mathrm{BH}_{3}$. Transition states $\mathbf{T 1 y}(\mathbf{M})$ leading to the cleavage of the $\mathrm{B}-\mathrm{H}$ bonds in such a case are higher in energy (Fig. 2, dashed lines). Activation energies are 27.8, 30.3 and $31.9 \mathrm{kcal} \mathrm{mol}^{-1}$ for 1, 2, and 3, respectively. The pathways go through the formation of a kite-shaped $\mathbf{M}_{3} \mathrm{H}$ arrangement in $\mathbf{T 1 y}(\mathbf{M})$ and the subsequent E1y(M). Similar kite-shaped $\mathrm{Li}_{3} \mathrm{H}$ moieties were found by

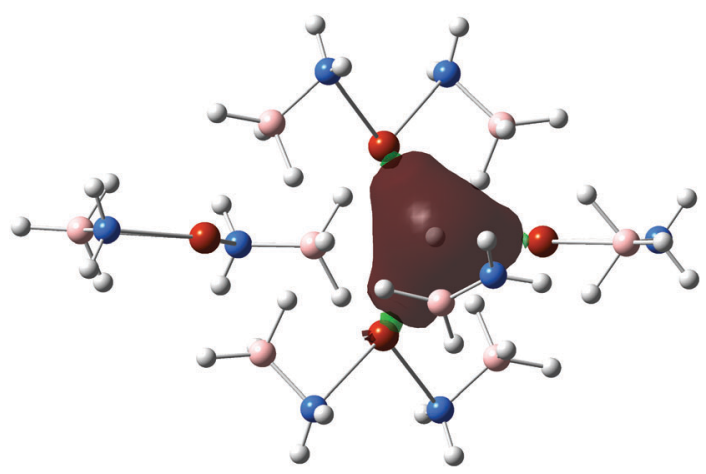

Fig. 3 The highest bonding orbital of E1z(Ca) local minimum. Red refers to $\mathrm{Ca}$ atoms, blue to $\mathrm{N}$, orange to $\mathrm{B}$ and white to $\mathrm{H}$ atoms.
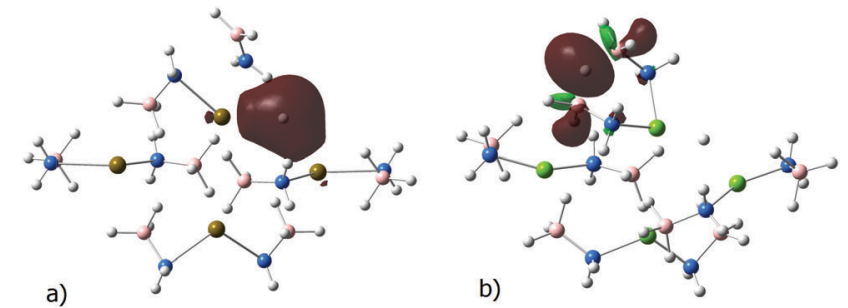

Fig. 4 Optimized structures and the highest bonding orbitals of E1y(M), $M=S r(a)$ and $M g$ (b). Brown/green refers to $\mathrm{Sr} / \mathrm{Mg}$ atoms, blue to $\mathrm{N}$, orange to $\mathrm{B}$ and white to $\mathrm{H}$ atoms.

GRRM $^{26}$ scanning of B-H bond cleavage pathways for LiAB tetramers. ${ }^{23}$ While intermediates E1y(Ca) and E1y(Sr) are similar, $\mathbf{E 1 y}(\mathbf{M g})$ is quite different. The local minima E1y(M) are shown in Fig. 4. In the case of $\mathrm{Ca}$ and $\mathrm{Sr}$, the highest bonding orbitals are delocalized over the removed $\mathrm{H}$ atom and two neighboring metal atoms, and the $\mathrm{NH}_{2} \mathrm{BH}_{2}$ intermediate is released (Fig. 4a). As in the case of the z-pathway, $\mathbf{E 1 y}(\mathbf{C a})$ and $\mathbf{E 1 y}(\mathbf{S r})$ are only slightly lower in energy than the respective transition states $\mathbf{T 1 y}(\mathbf{M})$. In the case of $\mathrm{Mg}$, the release of the $\mathrm{NH}_{2} \mathrm{BH}_{2}$ intermediate is not observed. Instead, $\left[\mathrm{BH}_{3} \mathrm{NH}_{2} \mathrm{CaNH}_{2} \mathrm{BH}_{2}\right]^{+}$is formed, where one $\mathrm{H}$ bridges two $\mathrm{BH}_{2}$ groups (Fig. $4 \mathrm{~b}$ ). This significantly stabilizes the $\mathbf{E} 1 \mathbf{y}(\mathbf{M g})$ state $\left(\Delta E_{0}^{\circ}=11.1 \mathrm{kcal} \mathrm{mol}^{-1}\right)$.

\section{Dehydrogenation from the same $\mathrm{NH}_{2} \mathrm{BH}_{3}$ group}

Dehydrogenation implies the cleavage of $\mathrm{N}-\mathrm{H}$ bonds in the $\mathrm{NH}_{2} \mathrm{BH}_{2}$ intermediate with the subsequent release of $\mathrm{H}_{2}$ molecules. This pathway is analogous to the D-path considered by Kim et al. ${ }^{21}$ for $\mathrm{M}\left(\mathrm{NH}_{2} \mathrm{BH}_{3}\right)_{2}(\mathrm{M}=\mathrm{Mg}$ and $\mathrm{Ca})$. While the first step involves the cleavage of the $\mathrm{B}-\mathrm{H}$ bonds in the $\mathrm{NH}_{2} \mathrm{BH}_{3}$ group, $\mathrm{H}_{2}$ is released in the next step via the $\mathrm{M}-\mathrm{H} \cdot \cdots \mathrm{H}-\mathrm{N}$ transition state. According to Kim et al., ${ }^{21}$ for $\mathrm{Ca}\left(\mathrm{NH}_{2} \mathrm{BH}_{3}\right)_{2}$ these steps are nearly equal in energy ( $\sim 36 \mathrm{kcal} \mathrm{mol}^{-1}$ at the MP2/6-311++G** level of theory). The dehydrogenation step for $\mathrm{Mg}\left(\mathrm{NH}_{2} \mathrm{BH}_{3}\right)_{2}$ has about the same energy barrier $\left(\sim 36 \mathrm{kcal} \mathrm{mol}^{-1}\right)$ but the cleavage of the $\mathrm{B}-\mathrm{H}$ bonds proceeds more easily $\left(\sim 24 \mathrm{kcal} \mathrm{mol}^{-1}\right)$.

The dehydrogenation steps for the $z$ - and $y$-pathways are denoted as $\mathbf{T} 2 \mathbf{z}(\mathbf{M})$ and $\mathbf{T} 2 \mathbf{y}(\mathbf{M})$, respectively (Fig. 2); optimized structures for $\mathrm{M}=\mathrm{Ca}$ are shown in Fig. 5. IRC defines local minima, $\mathbf{E} 1^{\prime} \mathbf{z}(\mathbf{M}) / \mathbf{E} 1^{\prime} \mathbf{y}(\mathbf{M})$, which are connected to $\mathbf{E 1 z}(\mathbf{M})$ / $\mathbf{E 1 y}(\mathbf{M})$ via additional steps, $\mathbf{T} 1^{\prime} \mathbf{z}(\mathbf{M}) / \mathbf{T} 1^{\prime} \mathbf{y}(\mathbf{M})$, with low energy barriers between them (Fig. 2). Transition states leading to the formation of $\mathrm{H}_{2}$ are the key states for the $z$ - and $y$-pathways with activation energies ranging from 40.9 to $44.4 \mathrm{kcal} \mathrm{mol}^{-1}$ (Fig. 2). The $\mathbf{M}_{3} \mathrm{H}$ pyramidal moiety in $\mathbf{T} 2 \mathbf{z}(\mathbf{M})$ and the $\mathbf{M}_{3} \mathrm{H}$ kite-shaped arrangement in $\mathbf{T} 2 \mathbf{y}(\mathbf{M})$ are destroyed (Fig. 5a). The hydrogen atoms in the transition states are located between two $\mathrm{M}$ atoms. The destruction of the $\mathbf{M}_{3} \mathrm{H}$ pyramidal moiety requires somewhat higher energy barriers. The $\mathbf{T} \mathbf{2 z}(\mathbf{M})$ energies increase in the order $\mathrm{Mg}<\mathrm{Ca}<\mathrm{Sr}$. It should be noted that the IRC scan leads to the intermediate $\mathbf{E 2 z}(\mathbf{M g})$, which is somewhat different from $\mathbf{E} 2 z(\mathbf{C a})$ and $\mathbf{E} 2 z(\mathbf{S r})$ (see the ESI, $\dagger$ Fig. S2).

While E2z(Ca) and $\mathbf{E 2 z}(\mathbf{S r})$ are lower in energy with respect to $\mathbf{E 2 z}^{*}(\mathbf{M})$ and free $\mathrm{H}_{2}$ molecules, E2z(Mg) is higher in energy (Fig. 2). 


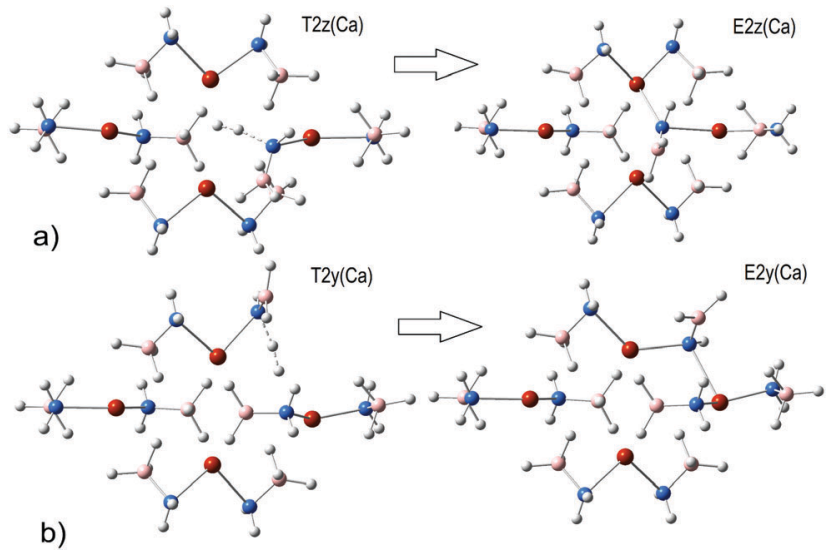

Fig. 5 Transition states and the final products for $z-(a)$ and $y$ - (b) pathways for $\left[\mathrm{Ca}\left(\mathrm{NH}_{2} \mathrm{BH}_{3}\right)_{2}\right]_{4}$.

For the sake of comparison, we also explored a direct dehydrogenation pathway which proceeds through hydrogen evolution via $\mathrm{N}-\mathrm{H}^{\delta+} \cdots \mathrm{H}^{\delta-}-\mathrm{B}$ interaction in the same $\mathrm{NH}_{2} \mathrm{BH}_{3}$ group. This pathway was found to be the most favorable for the CaAB dimer in the theoretical study of Yuan et al. ${ }^{22}$ (TS could be as low as $21.7 \mathrm{kcal} \mathrm{mol}^{-1}$ computed within an extended unit cell PBE/PAW method). The direct intramolecular dehydrogenation pathway was also assumed for $\mathrm{CaAB}$ and $\mathrm{MgAB}$ thermal decomposition in the theoretical study of Wang et al. ${ }^{16}$ The release of the first $\mathrm{H}_{2}$ molecule requires to overcome a barrier of $69.0 \mathrm{kcal} \mathrm{mol}^{-1}$ for $\mathrm{MgAB}$ and $73.5 \mathrm{kcal}^{-1}$ for $\mathrm{CaAB}$ at the $\operatorname{CCSD}(\mathrm{T}) /$ $6-311++G(3 d, 2 p)$ level of theory. ${ }^{16}$ In the present study on the example of 2 we found this pathway to be the most energetically demanding. The energy of the $\mathrm{N}-\mathrm{H} \cdots \mathrm{H}-\mathrm{B}$ transition state (Fig. S3 in the ESI $\dagger$ ) leading to the release of the first $\mathrm{H}_{2}$ molecule from $x-\mathrm{NH}_{2} \mathrm{BH}_{3}$ is $59.7 \mathrm{kcal} \mathrm{mol}^{-1}$. Optimization of the corresponding transition states for $y$ - and $z-\mathrm{NH}_{2} \mathrm{BH}_{3}$ converged to the alternative transition states $\mathbf{T} 2 \mathbf{z}(\mathbf{M}) / \mathbf{T} 2 \mathbf{y}(\mathbf{M})$ considered above.

\section{Oligomerization pathways}

An oligomerization pathway going through $\mathrm{B}-\mathrm{N}$ bond formation between $\mathrm{NH}_{2} \mathrm{BH}_{3}$ and $\mathrm{NH}_{2} \mathrm{BH}_{2}$ units was found to be the most favorable in the case of $\mathrm{LiAB}$ tetramers. ${ }^{23}$ Compared with the D-path, the O-path was found to be more favorable for LiAB, $\mathrm{KAB}$, and $\mathrm{NaAB}$ dimers and less favorable for $\mathrm{CaAB}$ and $\mathrm{MgAB}$ monomers in Kim's study. ${ }^{21}$

For tetramers, considered in the present work, B-N bond formation between $\mathrm{NH}_{2} \mathrm{BH}_{3}$ and $\mathrm{NH}_{2} \mathrm{BH}_{2}$ units can proceed along both $z$ - and $y$ - pathways. Oligomerization pathways are structurally similar for $\mathrm{M}=\mathrm{Mg}, \mathrm{Ca}$ and $\mathrm{Sr}$. As an example, structural transformation leading to the $\mathrm{B}-\mathrm{N}$ bond formation along the $z$-pathway is shown in Fig. 6 for $\mathrm{M}=\mathrm{Ca}$. The $\mathrm{Ca}_{3} \mathrm{H}$ moiety is retained along the oligomerization pathway. Structural transformations along the $y$-pathway are analogous (ESI, $\dagger$ Fig. S4). The energy diagram is presented in Fig. 7. T3y(M) energies in the oligomerization step (30.5 and $33.2 \mathrm{kcal} \mathrm{mol}^{-1}$ for $\mathrm{M}=\mathrm{Ca}$ and $\mathrm{Sr}$, respectively) are similar to those leading to the cleavage of the B-H bonds. For the z-pathway the oligomerization step is more energetically demanding than the first $\mathbf{T 1 z}(\mathbf{M})$ step by

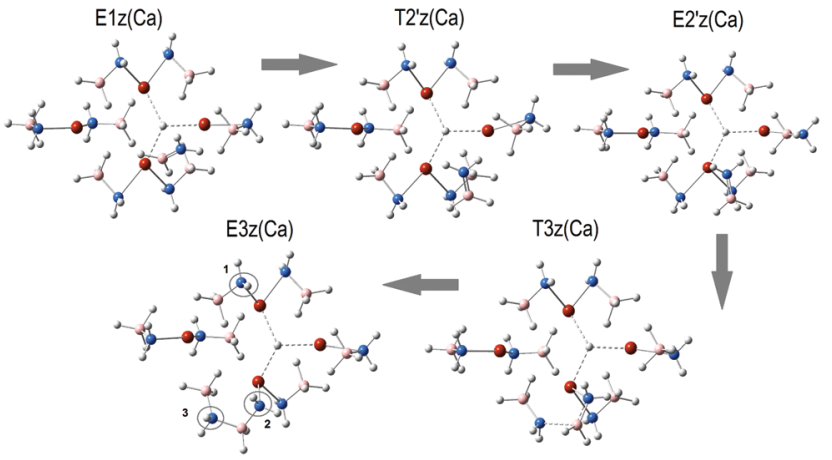

Fig. 6 Oligomerization $z$-pathway for $\left[\mathrm{Ca}\left(\mathrm{NH}_{2} \mathrm{BH}_{3}\right)_{2}\right]_{4}$. Dashed lines show the $\mathrm{Ca}_{3} \mathrm{H}$ pyramidal moiety. For $\mathrm{E3z}(\mathrm{Ca})$, the number of sites of $\mathrm{NH}_{2}$ groups is shown.

3-5 $\mathrm{kcal} \mathrm{mol}^{-1}$, but somewhat lower in energy than the oligomerization step for the $y$-pathway. Energies of $\mathbf{T} 3 \mathbf{z}(\mathbf{M})$ are 17.3, 26.4, and $28.0 \mathrm{kcal} \mathrm{mol}^{-1}$ for $\mathrm{M}=\mathrm{Mg}, \mathrm{Ca}$ and $\mathrm{Sr}$, respectively. Formation of the B-N bond significantly stabilizes $\mathbf{E 3 z}(\mathbf{M})$ though it is still notably endothermic for $\mathbf{M}=\mathrm{Ca}$ and $\mathrm{Sr}$. In contrast, formation of $\mathbf{E} \mathbf{z} \mathbf{z}(\mathbf{M g})$ is slightly exothermic $\left(-0.2 \mathrm{kcal} \mathrm{mol}^{-1}\right)$, and after an isomerization step via $\mathbf{T} 3^{\prime} \mathbf{z}(\mathbf{M g})$, formation of the $\mathbf{E} 3^{\prime} \mathbf{z}(\mathbf{M g})$ product is exothermic by $-8.1 \mathrm{kcal} \mathrm{mol}^{-1}$ (see Fig. 7).

The dehydrogenation step implies further cleavage of $\mathrm{N}-\mathrm{H}$ bonds. Possible sites of involved $\mathrm{NH}_{2}$ groups are shown in Fig. 6 for the product $\mathbf{E} \mathbf{3 z}(\mathbf{M})$. Five transition states found for the dehydrogenation of $\mathbf{E 3 z}(\mathbf{C a})$ are given in Fig. S5, ESI. $\dagger$ Energies of $\mathbf{T 4 z}(\mathbf{C a})$ vary from 43 to $53 \mathrm{kcal} \mathrm{mol}^{-1}$. The dehydrogenation transition states $\mathbf{T 4 z}(\mathbf{M})$ in the oligomerization pathway are higher in energy than $\mathbf{T} \mathbf{2 z}(\mathbf{M})$ in the pathway avoiding the oligomerization step, similar to previous findings for the alkaline-earth amidoborane monomers. ${ }^{21}$

The lowest energy barrier corresponds to the transition state leading to the hydrogen release from site number 3 where the $\mathrm{NH}_{2}$ group is associated with two B atoms. The transition state,

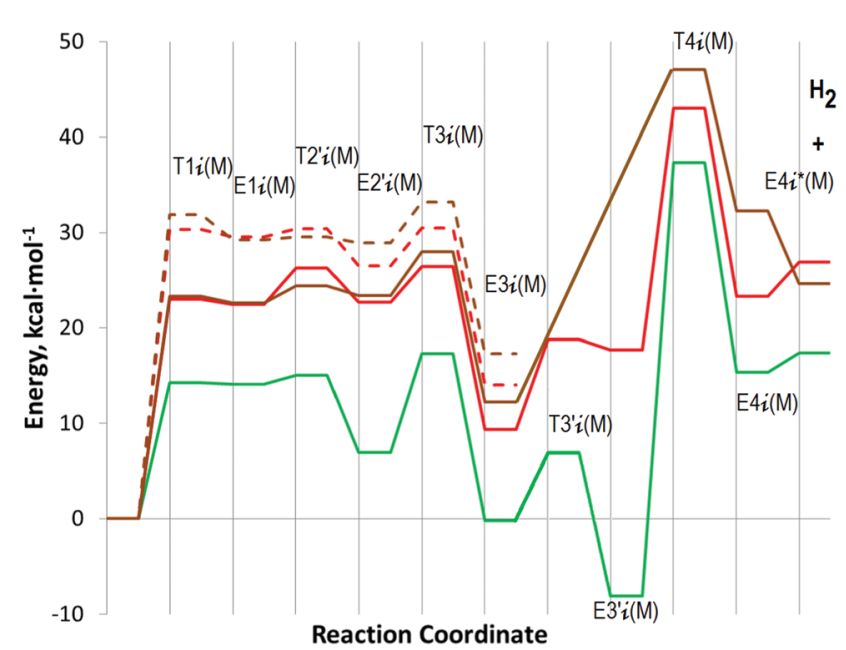

Fig. 7 Energy diagram of oligomerization pathways for $\left[\mathrm{M}\left(\mathrm{NH}_{2} \mathrm{BH}_{3}\right)_{2}\right]_{4}$, $M=M g$ (green), $C a(r e d)$ and $\operatorname{Sr}$ (brown). Lines $(i=z)$ refer to the $z$-path and dashed lines $(i=y)$ refer to the $y$-path. 


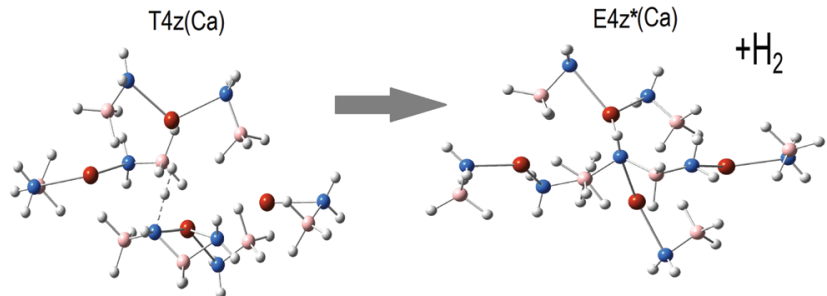

Fig. 8 The lowest transition state, $\mathbf{T} 4 \mathbf{z}(\mathrm{Ca})$, and the product of $\mathrm{H}_{2}$ release, $\mathrm{E} 4 \mathbf{z}^{*}(\mathrm{Ca})$, from $\left[\mathrm{Ca}\left(\mathrm{NH}_{2} \mathrm{BH}_{3}\right)_{2}\right]_{4}$ via an oligomerization pathway.

$\mathbf{T 4 z}(\mathbf{C a})$, and its product $\mathbf{E 4 z ^ { * }}(\mathbf{C a})$ are shown in Fig. 8. Similar transition states also exist in the case of $\mathrm{Mg}$ and $\mathrm{Sr}$. The energies of the states are $37.3,43.0$ and $47.1 \mathrm{kcal} \mathrm{mol}^{-1}$ for $\mathrm{M}=\mathrm{Mg}$, Ca and $\mathrm{Sr}$, respectively. The final product of the step is notably endothermic for all considered tetramers; $\Delta E_{0}^{\circ}\left(\mathbf{E} 4 z^{*}(\mathbf{M})+\mathrm{H}_{2}\right)$ is 17.4, 26.9, and 24.6 for $\mathrm{M}=\mathrm{Mg}, \mathrm{Ca}$, and $\mathrm{Sr}$, respectively.

It should be noted that the energy of the lowest dehydrogenation transition state from the $\left[\mathrm{LiNH}_{2} \mathrm{BH}_{3}\right]_{4}$ cluster is $31.2 \mathrm{kcal} \mathrm{mol}^{-1}$ at the M06/6-311(d,p) computational level. The energy of the lowest transition state leading to the oligomerization is $25.5 \mathrm{kcal} \mathrm{mol}{ }^{-1} \cdot{ }^{23}$ Analogous values for tetramer 2 at the same level of theory are $42.6 \mathbf{T 4 z}(\mathbf{C a})$ and $26.0 \mathrm{~T} 3 \mathrm{z}(\mathrm{Ca}) \mathrm{kcal} \mathrm{mol}^{-1}$. While oligomerization in the case of $\left[\mathrm{Ca}\left(\mathrm{NH}_{2} \mathrm{BH}_{3}\right)_{2}\right]_{4}$ needs to overcome nearly the same energy barrier as that in the case of $\left[\mathrm{LiNH}_{2} \mathrm{BH}_{3}\right]_{4}$, the dehydrogenation step is significantly more energy consuming. Presumably the reason is the better mobility of the closed shell $\mathrm{LiH}$ unit formed after the cleavage of the $\mathrm{B}-\mathrm{H}$ bond. In contrast to $\mathrm{LiAB}$ tetramers, the diamond-shaped arrangement of metal atoms in 2 is maintained in the cluster during all transformations in the reaction direction.

While $\mathrm{H}_{2}$ elimination is a major result of thermal decomposition of MAB, some amount of ammonia release is observed experimentally. ${ }^{6,7,13}$ According to the mechanisms of the thermal decomposition of the alkali-metal amidoboranes suggested by Fijalkowski et al., ${ }^{8}$ this secondary $\mathrm{NH}_{3}$ release proceeds via the $\mathrm{B}-\mathrm{N}$ bond cleavage accompanied by intermolecular transfer of $\mathrm{H}^{\delta+}$ and intermediate formation of weakly bonded $\left[\mathrm{MNH}_{3}\right]^{+}$ cations. To estimate whether the cleavage of $\mathrm{B}-\mathrm{N}$ bonds in alkaline-earth metal amidoboranes is a competitive process with the $\mathrm{H}_{2}$ elimination mechanisms suggested above, we considered several B-N bond breaking pathways in 2. Three different transition states leading to the cleavage of $\mathrm{B}-\mathrm{N}$ bonds of $z-\mathrm{NH}_{2} \mathrm{BH}_{3}$ are provided in the ESI $\dagger$ (Fig. S6). One of the possibilities, $\mathbf{T} 5 \mathbf{z}(\mathbf{C a})$, leads to the formation of $\left[\mathrm{CaNH}_{3}\right]^{+}$cations in $\mathbf{E 5 z}(\mathbf{C a})$. However, the activation energy is $81.1 \mathrm{kcal} \mathrm{mol}^{-1}$, i.e. 3.5 times larger than the activation energy of $\mathrm{B}-\mathrm{H}$ bond cleavage via $\mathbf{T 1 z}(\mathbf{C a})$, and about twice as large as that of the key state for $\mathrm{H}_{2}$ release via the oligomerization pathway, $\mathbf{T 4 z}(\mathbf{C a})$. Transfer of $\mathrm{BH}_{3}$ to one of the $y-\mathrm{NH}_{2} \mathrm{BH}_{3}$ units is accompanied by the occupation of the $\left[\mathrm{NH}_{2}\right]^{-}$residue at the position between three Ca atoms forming a pyramidal $\mathrm{Ca}_{3} \mathrm{NH}_{2}$ moiety analogously to the $\mathrm{Ca}_{3} \mathrm{H}$ moiety discussed above. One of the transition states, $\mathbf{T 6 z}(\mathbf{C a})$ with an energy of $50.8 \mathrm{kcal} \mathrm{mol}^{-1}$, leads to bridging of the released $\mathrm{BH}_{3}$ with the $\mathrm{BH}_{3}$ group of $y-\mathrm{NH}_{2} \mathrm{BH}_{3}$ by the $\mathrm{H}$ atom. The other transition state, $\mathbf{T} 7 \mathbf{z}(\mathbf{C a})$ with an energy of
$51.3 \mathrm{kcal} \mathrm{mol}^{-1}$, leads to head-to-tale dimerization with the formation of a $\left[\mathrm{BH}_{3} \mathrm{NH}_{2} \mathrm{BH}_{3}\right]^{-}$unit. Thus, it follows that $\mathrm{B}-\mathrm{N}$ bond breaking pathways have larger activation energies than $\mathrm{H}_{2}$ elimination pathways. This is consistent with the minor role of mechanisms leading to the release of ammonia.

\section{Computational details}

The conventional transition state theory was used to predict the optimized structures and transition states of $\left[\mathrm{M}\left(\mathrm{NH}_{2} \mathrm{BH}_{3}\right)_{2}\right]_{4}$ tetramers, where $\mathrm{M}=\mathrm{Mg}, \mathrm{Ca}$, and $\mathrm{Sr}$. The intrinsic reaction coordinate (IRC) scans confirmed the connectivity of all the transition states to reactants and products of a given step. It was noted in previous theoretical investigations that taking into account van der Waals interactions is important to reproduce experimental parameters of SrAB. ${ }^{20}$ All computations were performed within DFT using the $\mathrm{M}^{2} 6^{27}$ functional, which takes dispersion interaction into account. The $\mathrm{TZVP}^{28}$ basis set was used throughout. The same computation level was used for the Natural Bond Orbital (NBO) analysis. ${ }^{29}$ The Gaussian 09 code $^{30}$ was utilized in all computations.

\section{Conclusion}

A cluster approximation was used to explore the release of the first $\mathrm{H}_{2}$ molecule from alkaline-earth metal amidoboranes. To form the cluster, geometries of four neighboring molecules were extracted from a layer of experimental crystal structure of CaAB. The cleavage of $\mathrm{B}-\mathrm{H}$ bonds in the $\mathrm{NH}_{2} \mathrm{BH}_{3}$ unit in the environment of alkaline-earth metal atoms leads to the "capture" of the released $\mathrm{H}$ atom by neighboring metal atoms with the formation of a $\mathrm{M}_{3} \mathrm{H}$ moiety. Such a moiety was found to be a key feature of the dehydrogenation process in small (trimeric and tetrameric) LiAB clusters. ${ }^{23,24}$ The formation of this $\mathrm{Li}_{3} \mathrm{H}$ moiety was ascribed to the existence of stable $\mathrm{Li}_{3} \mathrm{H}$ clusters. ${ }^{31,32}$ Despite the fact that similar free $\mathrm{M}_{3} \mathrm{H}$ clusters are not found in alkaline-earth metal hydrides (unlike $\mathrm{Li}_{3} \mathrm{H}, \mathrm{Ca}_{3} \mathrm{H}$ is an open shell construct), the $\mathrm{M}_{3} \mathrm{H}$ moiety ( $\mathrm{M}=\mathrm{Mg}, \mathrm{Ca}$, and $\mathrm{Sr}$ ) plays an important role in the structural transformations of alkaline-earth metal amidoboranes. The $\mathrm{M}_{3} \mathrm{H}$ moiety has a delocalized bonding orbital and the $\mathrm{M}-\mathrm{H}$ bond lengths are only slightly larger than the sum of the respective covalent radii.

While the cleavage of the $\mathrm{B}-\mathrm{H}$ bonds and further oligomerization of amidoboranes require moderate energy, the cleavage of $\mathrm{N}-\mathrm{H}$ bonds accompanied by destruction of the $\mathrm{M}_{3} \mathrm{H}$ moiety in favor of $\mathrm{H}_{2}$ formation is much more energy consuming. This step requires significant energy uptake both for oligomerization and non-oligomerization pathways.

Kinetically, after the cleavage of the first B-H bond, the cleavage of other B-H bonds or/and oligomerization with $\mathrm{B}-\mathrm{N}$ bond formation require much less energy uptake than a direct $\mathrm{H}_{2}$ release. This indicates that compounds featuring $\mathrm{MNH}_{2} \mathrm{BH}_{2} \mathrm{NH}_{2} \mathrm{BH}_{3}$ units are potential intermediates in the dehydrogenation process. The large number of possible isomers of such compounds makes the use of a convenient transition state method ineffective for 
the exploration of pathways for the release of second and subsequent hydrogen molecules. In such a situation, use of the $\mathrm{GRRM}^{26}$ method is recommended for further studies.

The cleavage of $\mathrm{B}-\mathrm{N}$ bonds is found to be significantly less favorable than the cleavage of $\mathrm{B}-\mathrm{H}$ bonds. If local overheating leads to the $\mathrm{B}-\mathrm{N}$ bond cleavage, then the formation of the $\mathrm{M}_{3} \mathrm{NH}_{2}$ moiety is more favorable than the formation of the $\mathrm{MNH}_{3}$ complex. This may be accompanied by the formation of an intermediate $\left[\mathrm{BH}_{3} \mathrm{NH}_{2} \mathrm{BH}_{3}\right]^{-}$or the release of diborane. The following $\mathrm{NH}_{3}$ release is likely to be a multistep side process which requires additional studies which are outside the scope of the present research.

Tetramers of alkaline-earth metal ( $\mathrm{Mg}, \mathrm{Ca}$ and $\mathrm{Sr}$ ) amidoboranes show similar tendencies along the reaction pathways with energy barriers increasing in the order $\mathrm{Mg}<\mathrm{Ca} \leq \mathrm{Sr}$. However, according to experiments, ${ }^{11}$ a higher temperature is required for the start of the dehydrogenation in the case of $\mathrm{MgAB}$, which suggests a larger barrier for $\mathrm{H}_{2}$ release from $\mathrm{MgAB}$ compared to $\mathrm{CaAB}$ and $\mathrm{SrAB}$. One of the reasons for this disagreement could be our assumption of a similar crystal structure for $\mathrm{MaAB}$ and $\mathrm{CaAB}$, and, consequently, a similar local environment of the atoms in tetramer clusters $\mathbf{1}$ and $\mathbf{2}$. Note that previous computational studies based on such an assumption also resulted in lower energy barriers for the thermal decomposition of $\mathrm{MgAB}$ compared to $\mathrm{CaAB} .{ }^{18}$ In the present study, we demonstrate that unlike $\mathrm{Ca}$ and $\mathrm{Sr}$, in the case of $\mathrm{Mg}$, oligomerization of $\mathrm{NH}_{2} \mathrm{BH}_{3}$ and $\mathrm{NH}_{2} \mathrm{BH}_{2}$ units in 1 makes the formation of the $\mathbf{E 3}^{\prime} \mathbf{z}(\mathbf{M g})$ intermediate exothermic and significantly increases the activation energy for the subsequent dehydrogenation steps. We suppose that similar transformations occur in the crystal structure of $\mathrm{MgAB}$ prior to the dehydrogenation which increases the overall activation energy for $\mathrm{MgAB}$ dehydrogenation compared to $\mathrm{CaAB}$ and $\mathrm{SrAB}$.

\section{Acknowledgements}

This work was financially supported by the Russian Science Foundation grant 14-13-00151. This research was carried out using computational resources provided by the Resource Center "Computer Center of SPbU".

\section{References}

1 W. Grochala and P. P. Edwards, Chem. Rev., 2004, 104, 1283.

2 S. Orimo, Y. Nakamori, J. R. Eliseo, A. Züttel and C. M. Jensen, Chem. Rev., 2007, 107, 4111.

3 Y. S. Chua, P. Chen, G. Wua and Z. Xionga, Chem. Commun., 2011, 47, 5116.

4 R. Owarzany, P. J. Leszczyński, K. J. Fijalkowski and W. Grochala, Crystals, 2016, 6, 88.

5 Z. Xiong, C. K. Yong, G. Wu, P. Chen, W. Shaw, A. Karkamkar, T. Autrey, M. O. Jones, S. R. Johnson, P. P. Edwards and W. I. F. David, Nat. Mater., 2008, 7, 138.

6 K. J. Fijalkowski and W. Grochala, J. Mater. Chem., 2009, 19, 2043.
7 K. J. Fijalkowski, R. V. Genova, Y. Filinchuk, A. Budzianowski, M. Derzsi, T. Jaroń, P. J. Leszczyński and W. Grochala, Dalton Trans., 2011, 40, 4407.

8 K. J. Fijalkowski, T. Jaroń, P. J. Leszczyński, E. MagosPalasyuk, T. Palasyuk, M. K. Cyrańskic and W. Grochala, Phys. Chem. Chem. Phys., 2012, 14, 5778.

9 K. J. Fijalkowski, R. Jurczakowski, W. Koźmińskia and W. Grochala, Phys. Chem. Chem. Phys., 2014, 16, 23340.

10 R. Owarzany, K. J. Fijalkowski, T. Jaroń, P. J. Leszczyński, Ł. Dobrzycki, M. K. Cyrański and W. Grochala, Inorg. Chem., 2016, 55, 37.

11 J. Luo, X. Kang and P. Wang, Energy Environ. Sci., 2013, 6, 1018.

$12 \mathrm{H}$. Wu, W. Zhou and T. Yildirim, J. Am. Chem. Soc., 2008, 130, 14834.

13 Q. G. Zhang, C. X. Tang, C. H. Fang, F. Fang, D. Sun, L. Z. Ouyang and M. Zhu, J. Phys. Chem. C, 2010, 114, 1709.

14 H. V. K. Diyabalanage, R. P. Shrestha, T. A. Semelsberger, B. L. Scott, M. E. Bowden, B. L. Davis and A. K. Burrell, Angew. Chem., Int. Ed., 2007, 46, 8995.

15 Y. Zhang and C. Wolverton, J. Phys. Chem. C, 2012, 116, 14224.

16 K. Wang, V. Arcisauskaite, J.-S. Jiao, J.-G. Zhang, T.-L. Zhang and Z.-N. Zhou, RSC Adv., 2014, 4, 14624.

17 Y. Zhang, T. Autrey and C. Wolverton, J. Phys. Chem. C, 2012, 116, 26728.

18 W. Li, G. Wu, Y. Chua, Y. P. Feng and P. Chen, Inorg. Chem., 2012, 51, 76.

19 C. B. Lingam, K. R. Babu, S. P. Tewari, G. Vaitheeswaran and S. Lebègue, J. Phys. Chem. C, 2011, 115, 18795.

20 B. L. Chittari and S. P. Tewari, Mater. Chem. Phys., 2014, 148, 364.

21 D. Y. Kim, H. M. Lee, J. Seo, S. K. Shin and K. S. Kim, Phys. Chem. Chem. Phys., 2010, 12, 5446.

22 P.-F. Yuan, F. Wang, Q. Sun, Y. Jia and Z. X. Guo, Int. J. Hydrogen Energy, 2013, 38, 11313.

23 A. V. Pomogaeva, K. Morokuma and A. Y. Timoshkin, J. Phys. Chem. A, 2016, 120, 145.

24 A. V. Pomogaeva, K. Morokuma and A. Y. Timoshkin, J. Comput. Chem., 2016, 37, 1259.

25 Y. S. Chua, G. Wu, Z. Xiong, A. Karkamkar, J. Guo, M. Jian, M. W. Wong, T. Autrey and P. Chen, Chem. Commun., 2010, 46, 5752 .

26 S. Maeda, K. Ohno and K. Morokuma, Phys. Chem. Chem. Phys., 2013, 15, 3683.

27 Y. Zhao and D. G. Truhlar, Theor. Chem. Acc., 2008, 120, 215.

28 F. Weigend and R. Ahlrichs, Phys. Chem. Chem. Phys., 2005, 7, 3297.

29 E. D. Glendening, A. E. Reed, J. E. Carpenter and F. Weinhold, NBO Version 3.1.

30 M. J. Frisch, G. W. Trucks, H. B. Schlegel, G. E. Scuseria, M. A. Robb, J. R. Cheeseman, G. Scalmani, V. Barone, B. Mennucci and G. A. Petersson, et al., Gaussian 09, Revision C.01, Wallingford, CT, 2009.

31 C. H. Wu and R. O. Jones, J. Chem. Phys., 2004, 120, 5128.

32 J. A. Jr. Montgomery, H. H. Michels, O. F. Guner and K. Lammertsma, Chem. Phys. Lett., 1989, 161, 291. 